\title{
Cellulose-Based Polymer Composite with Carbon Black for Tetrahydrofuran Sensing
}

\author{
Susana Hernández-López, ${ }^{1}$ Enrique Vigueras-Santiago, ${ }^{1}$ Miriam Mendoza Mora, \\ José Rurik Farias Mancilla, ${ }^{2}$ and Erasto Armando Zaragoza Contreras ${ }^{3}$ \\ ${ }^{1}$ Laboratorio de Investigación y Desarrollo de Materiales Avanzados (LIDMA), Facultad de Química, \\ Universidad Autónoma del Estado de México, Campus Rosedal, Paseo Colón Esquina con Paseo Tollocan s/n, \\ 50000 Toluca, MEX, Mexico \\ ${ }^{2}$ Universidad Autónoma de Ciudad Juárez, Avenida del Charro 450 Norte, 32310 Civdad Juárez, CHIH, Mexico \\ ${ }^{3}$ Centro de Investigación en Materiales Avanzados, S.C. Miguel de Cervantes No. 120, Complejo Industrial Chihuahua, \\ 31109 Chihuahua, CHIH, Mexico
}

Correspondence should be addressed to Susana Hernández-López; shernandezl@uaemex.mx

Received 21 May 2013; Revised 14 August 2013; Accepted 15 August 2013

Academic Editor: Gonzalo Martínez-Barrera

Copyright (C) 2013 Susana Hernández-López et al. This is an open access article distributed under the Creative Commons Attribution License, which permits unrestricted use, distribution, and reproduction in any medium, provided the original work is properly cited.

\begin{abstract}
This work focused on studying the sensing efficiency of tetrahydrofuran (THF) by composite films made of thin layers of a cellulosebased polymer and carbon black. We analyze the reproducibility, durability, desorption time, and the sensitivity percent as a function of the amount of solvent. Two types of experiments were conducted, (1) progressive sensing test (PST) which consisted of progressively increasing the amount of solvent from $0.1 \mathrm{~mL}$ increments up to $1.0 \mathrm{~mL}$ and (2) multiple sensing test (MST) where the layers were subjected to consecutive pulses of the same amount of solvent, with a minimum of $0.1 \mathrm{~mL}$ and a maximum of $0.4 \mathrm{~mL}$. The response and desorption times were a few seconds, and the sensitivity percent ranged from $1 \%$ to $170 \%$ and was dependent on the solvent quantity.
\end{abstract}

\section{Introduction}

The polymer/carbon particles composites using carbon black (CB) and carbon nanotubes (CNT) have been extensively investigated for detecting an array of solvent vapors [1-20]. These materials function at room temperature, and it is possible to detect a wide variety of compounds through the appropriate choice of polymer and conductive particles.

The most critical characteristics of these compounds, for use in sensors, are the sensibility, response and desorption times, and durability. Controlling of these parameters in polymer matrices made from renewable sources is of great interest, and there are many potential applications for use in vapor sensing devices.

Cellulose is the most abundant natural product, in addition to being biodegradable and renewable. It is a colorless polymer, insoluble in water, dilute acids and alkalis and in the most of organic solvents. In addition, cellulose can, via esterification and etherification reactions in pendant hydroxyl groups, yield a wide variety of derivates. Cellulose esters and ethers can be easily dissolved in aqueous and/or organic solvents. Acrylamidomethyl cellulose acetate butyrate ( $\mathrm{ACAB}$ ) is an ester derived from cellulose obtained by reacting cellulose acetate butyrate (CAB) with N-methylacrylamide (NMA) in an aqueous phase and in the presence of sulfuric acid catalyst. The product, a white powder, is used to produce copolymers with optimum processing properties [21] used in the fabrication of composite materials. Figure 1 shows the chemical structure and composition of ACAB.

In a previous paper [21], we studied the electrical properties of $\mathrm{ACAB}$ composites with carbon black. The composites exhibited a critical concentration of $3 \mathrm{wt} . \% \mathrm{CB}$. This property and ease of processing make $\mathrm{ACAB}$ an attractive material for sensing organic solvent vapors. In this work, we studied 


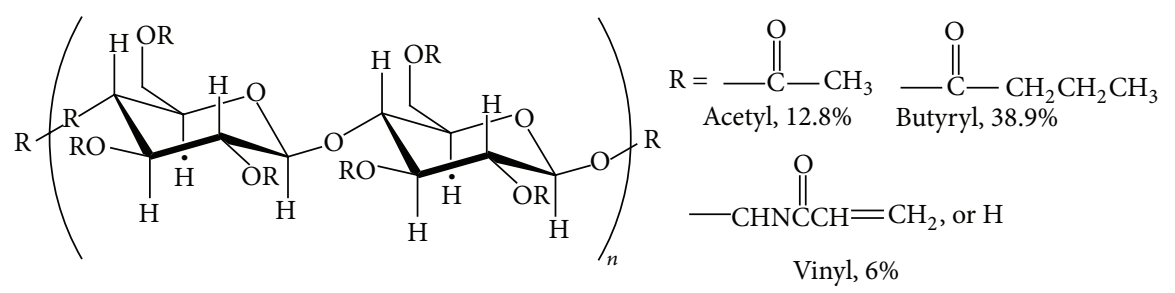

FIgURE 1: Structural representation and composition of commercial ACAB.

the THF vapor detection efficiency using thin layers of an $\mathrm{ACAB} / 10$ wt.\% CB composite. Sensitivity percent, response, relaxation times, and the durability were studied as a function of the amount of solvent. These parameters were evaluated in two types of experiments: (1) in the first experiment, progressive sensing test (PST), samples were subjected to pulses in which the amount of solvent was progressively increasing from $0.1 \mathrm{~mL}$ in $0.1 \mathrm{~mL}$ up to complete $1 \mathrm{~mL}$. This methodology was useful in determining the electrical behavior of the composite as a function of solvent level. This testing also served to establish the minimum and maximum limits of detection in the range of 0.1 to $1.0 \mathrm{~mL}$. (2) The second type of experiment, multiple sensing testing (MST), consisted of subjecting the composite layers to the same amount of solvent repeatedly until deterioration ensued. The fixed amounts established for this second experiment $(0.1$ and $0.4 \mathrm{~mL})$ were determined in accordance with the reproducibility of the results obtained in the PST experiment. Sensing experiments were carried out in an in-house designed chamber. The sample was placed in the chamber, conditioned via a flow of moisture-free air, and then exposed to controlled solvent amounts while the electrical resistance was monitored.

\section{Experimental Part}

2.1. Reactants. Acrylamidomethyl cellulose acetate butyrate (ACAB) was obtained from Sigma-Aldrich, Chemical Company. The number-average molecular weight, $M_{n}$ is about 10.000 as determined by GPC. The material is soluble in a variety of acrylic monomer. Other properties include: density of $1.31 \mathrm{~g} / \mathrm{mL}$ at $25^{\circ} \mathrm{C}$, viscosity of $60 \mathrm{cp}$ at $25^{\circ} \mathrm{C}, \mathrm{T}_{\mathrm{g}}$ of $118^{\circ} \mathrm{C}$, and $T_{m}$ of $146^{\circ} \mathrm{C}$. Carbon Black Vulcan XC72 was donated by Cabot Co. The particle size is in the range of $32 \mathrm{~nm}$, and conductivity is $10-10^{2} \mathrm{~S} / \mathrm{m}$. HPLC grade tetrahydrofuran (THF) was obtained from Sigma-Aldrich, Chemical Company Inc. It is a solvent with medium polarity that allows an optimum dispersion of carbon black [21-23] and dissolves ACAB. The molecular weight is $72.11 \mathrm{~g} / \mathrm{mol}$, the bp $66^{\circ} \mathrm{C}$, vapor pressure $19.3 \mathrm{kPa}$ at $20^{\circ} \mathrm{C}$, and density $0.88 \mathrm{~g} / \mathrm{cm}^{3}$. Silver Paint was provided by Electron Microscopy Sciences. It is a colloidal silver liquid with $72 \%$ in solids and a contact resistance of $1 \Omega$.

2.2. Preparation of the Polymer Composites. The polymer composites were prepared in accordance with the methodology reported in [21]. Layers of polymer composite were deposited on glass substrates of $2.5 \times 2.5 \mathrm{~cm}$, at a speed of $1000 \mathrm{rpm}$ in a spin coating system. Each layer of polymer was obtained by 10 consecutive deposits of $\mathrm{ACAB} / 10 \mathrm{wt} \% \mathrm{CB}$ dissolution, leaving a time of approximately 3 min between each deposit.

The layers were put in a vacuum for $24 \mathrm{hr}$ in order to remove the residual solvent. Electrical contacts were put on the layer composite by painting two parallel lines of silver paint with a distance of $1.5 \mathrm{~cm}$ of separation. The layers were selected in accordance with the range of their electrical resistance (a few $\mathrm{M} \Omega$ in order of magnitude) for each group of experiments.

2.3. Sensing Tests. THF vapors were detected using a system in which the electrical resistance of the layer is monitored with a multimeter STEREN MUL model 600 coupled to a computer. The layer first is subjected to a flow of moisturefree air and oil at a rate of $1 \mathrm{~L} / \mathrm{min}$. After that, the air is infused with controlled amounts of THF pulses. Each pulse is applied by injecting the respective amount of THF using graduate syringes. Between pulse and pulse, a 10 to $15 \mathrm{~min}$ is left so that the resistance returns to a stable value. The layer in relation to the air flow is always placed at a right angle as shown in Figure 2.

2.3.1. Progressive Sensing Test (PST). In this type of experiment, the layers were exposed to a progressive increasing of THF pulses in 5 samples with the same range of resistance, from 1 to $2 \mathrm{M} \Omega$. Pulses were applied from 0.1 to $1 \mathrm{~mL}$ with increments of $0.1 \mathrm{~mL}$. After the completion of all the pulses, the sample is put in a vacuum for $24 \mathrm{hr}$ to remove the residual solvent, and again it is exposed to the same process. This cycle is made repeatedly (5 times) in order to get a statistics.

2.3.2. Multiple Sensing Test (MST). This experiment used layers with the same range of resistance, from 2 to $3.5 \mathrm{M} \Omega$ for multiple sensing using $0.1 \mathrm{~mL}$ of solvent, and from 5 to 6.5 $\mathrm{M} \Omega$ for using $0.4 \mathrm{~mL}$. Layers were subjected to repetitive pulses of the same amount of THF until deterioration of the sample was detected. In all cases, this deterioration was identified by an interruption of the electrical signal or because the resistance values were not reproducible, outside of the average of the previous measurements.

\section{Results and Discussion}

3.1. Tests Progressive Sensing. The initial characteristics of the used samples are shown in Table 1.

Figure 3 illustrates a typical PST experiment. Each signal is produced in response to a pulse of solvent in quantities that increment from 0.1 to 0.1 up to $1 \mathrm{~mL}$, starting with $0.1 \mathrm{~mL}$. 
TABLE 1: Original resistance $\left(R_{0}\right)$ for the layers used in each test before any THF pulse.

\begin{tabular}{|c|c|c|c|c|c|}
\hline \multicolumn{2}{|c|}{ For PST } & \multicolumn{2}{|c|}{ For MST at $0.1 \mathrm{~mL}$} & \multicolumn{2}{|c|}{ For MST at $0.4 \mathrm{~mL}$} \\
\hline Sample & $R_{0}(\mathrm{M} \Omega)$ & Sample & $R_{0}(\mathrm{M} \Omega)$ & Sample & $R_{0}(\mathrm{M} \Omega)$ \\
\hline PST 1 & 1.637 & MST la & 3.539 & MST $1 b$ & 5.499 \\
\hline PST 2 & 1.181 & MST 2a & 3.328 & MST 2b & 6.190 \\
\hline PST 3 & 1.553 & MST 3a & 3.090 & MST $3 b$ & 6.559 \\
\hline PST 4 & 1.108 & MST 4a & 2.109 & MST $4 \mathrm{~b}$ & 6.288 \\
\hline PST 5 & 1.765 & MST 5a & 4.44 & MST 5b & 6.190 \\
\hline
\end{tabular}

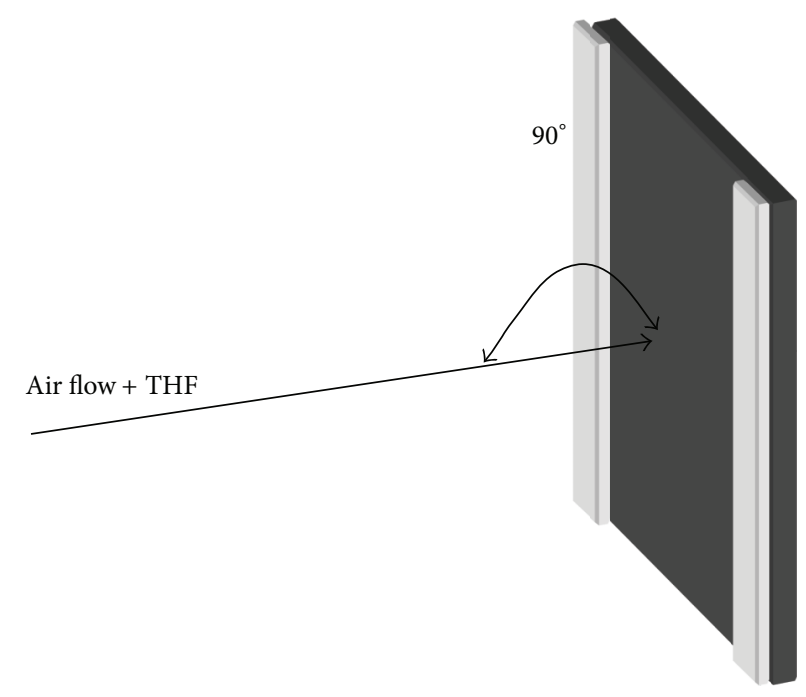

FIGURE 2: Experimental arrangement for sensing test.

The sensitivity percent, response, and desorption times were determined according to the definitions given in [24]. The resistance after a pulse never returns the $R_{0}$ value, being $R_{0}$ the original resistance before any pulse. The sensitivity of each pulse was calculated using the $R_{i}$ value corresponding to the value at which the resistance returns from the previous pulse. Figure 3 shows how $R_{i}$ value increases as the amount of solvent increases, and this is usually higher than the initial $R_{0}$ value. This effect could be the result of the fact that some solvent is retained by the layer and/or there is a modification of the initial configuration of the conductive networks derived from the swelling of the polymer matrix in contact with the solvent. A similar effect takes place in thin layers of polymer composites when they are exposed to several cycles of heat treatment [23]. The average value of the sensitivity percent is shown in Table 2.

As the amount of solvent increases, the detection sensitivity percent also increases. For a pulse of $1 \mathrm{~mL}$, the sensitivity percent is nearly 180 times greater than the sensitivity for a pulse of $0.1 \mathrm{~mL}$. In the PST experiment, the increase in sensitivity is almost linear between pulse and pulse, from 0.1 to $0.4 \mathrm{~mL}$. The percent of higher sensitivity is presented for THF volumes from 0.5 to $1.0 \mathrm{~mL}$; however, the error in the changes of sensitivity is higher than for volumes from 0.1 to $0.4 \mathrm{~mL}$. For all the THF volumes, the sensitivity percent is greater than the unit, which is an indication, as mentioned before, that the compound of $\mathrm{ACAB}$ with $\mathrm{CB}$ is a sensitive sensor to THF.
TABLE 2: Sensitivity average (SA), error percent, and response time for the progressive sensing tests.

\begin{tabular}{lccc}
\hline THF pulse $(\mathrm{mL})$ & SA $(\%)$ & Error $(\%)$ & $t_{R}(\mathrm{~s})$ \\
\hline 0.1 & 1.53 & \pm 1.34 & 11 \\
0.2 & 2.10 & \pm 3.32 & 13 \\
0.3 & 4.50 & \pm 22.23 & 13 \\
0.4 & 15.70 & \pm 98.21 & 24 \\
0.5 & 33.93 & \pm 43.00 & 11 \\
0.6 & 57.65 & \pm 11.45 & 15 \\
0.7 & 105.83 & \pm 37.42 & 9 \\
0.8 & 131.95 & \pm 33.74 & 8 \\
0.9 & 143.78 & \pm 7.58 & 4 \\
1 & 178.83 & \pm 17.68 & 2 \\
\hline
\end{tabular}

The response time is defined as the time that it takes until the detector reaches the $90 \%$ of the maximum resistance [24]. The average of the response time in the PST experiments is shown in Table 2 . In this type of experiments, the response times of the $\mathrm{ACAB}$ with $\mathrm{CB}$ composite to THF in the range of $0.1-1.0 \mathrm{~mL}$ take no longer than $24 \mathrm{~s}$, and this is very good for sensors derived from polymeric composites. The response times have a tendency to decrease with the amount of THF. This indicates that THF has to be absorbed via diffusion and swelling of the polymer matrix. This swelling produces a separation of the conductive particles and, in turn, a variation 

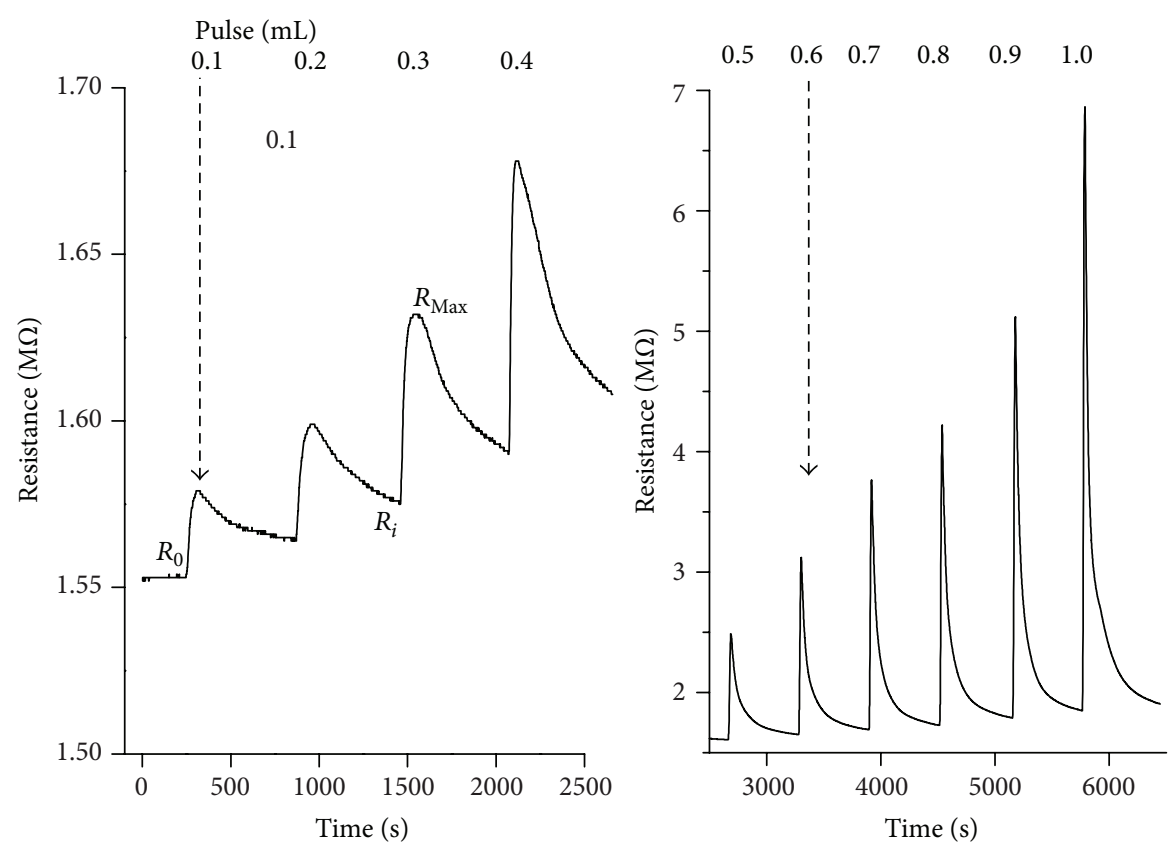

FIgUre 3: Progressive sensing test from 0.1 to $1 \mathrm{~mL}$ of THF for PST 3 sample.

in the electrical response or resistance. With a small amount of solvent, there is a slight penetration of the surface of the layer, and the change in resistance is not significant. As the amount of solvent increases, absorption and swelling are greater, and the response to the detection is incremental. In this case, the response is detected in the first few seconds that the composite material comes in contact with the solvent.

The desorption time is the time taken for the layer composite to release the absorbed solvent at a specific resistance value. This value corresponds to that at which the resistance has reached the $10 \%$ of its saturation value after it has decreased from the maximum value [24]. It is noticed that as the solvent amount increases there is a reduction in desorption times. A part of the solvent remains absorbed in the layer (as evidenced by the greater initial resistance in each subsequent pulse). When low amounts of solvent are used, most remains absorbed by the layer and desorption of minute amounts of it is a very slow process. For higher solvent amounts, some vapor also persist but the rest is desorbed immediately, making the desorption process faster.

3.2. Multiple Sensing Test (MST). The purpose of this experiment was to evaluate the reproducibility of the composite by applying a consecutive series of pulses using the same THF quantity. 0.1 and $0.4 \mathrm{~mL}$ quantities of THF were studied. The values of initial resistance for the composite layers are shown in Table 1. The results of the multiple sensing tests are shown in Figure 4(a). Each peak represents the response to an injected pulse of $0.1 \mathrm{~mL}$ THF. The average of the sensitivity percent of five samples subjected to 20 pulses of $0.1 \mathrm{~mL}$ in this MST experiment is displayed in Table 3.

The sensitivity percent is shown in Figure 4(b), and it is compared with the average value that is 1.77 . The percent error with respect to the media is $\pm 5.64 \%$. Thirty-five percent are
TABLe 3: Sensitivity average for the MST experiments to 0.1 and $0.4 \mathrm{~mL}$ THF.

\begin{tabular}{lcc}
\hline Test number & SA (\%) for $0.1 \mathrm{~mL}$ & SA (\%) for $0.4 \mathrm{~mL}$ \\
\hline 1 & 1,783 & 17.400 \\
2 & 1,859 & 19.300 \\
3 & 1,662 & 19.250 \\
4 & 1,799 & 19.700 \\
5 & 1,593 & 18.900 \\
6 & 1,873 & 16.600 \\
7 & 1,843 & 18.950 \\
8 & 1,674 & 18.100 \\
9 & 1,619 & 16.800 \\
10 & 1,560 & 18.700 \\
11 & 1,862 & - \\
12 & 1,825 & - \\
13 & 1,815 & - \\
14 & 1,773 & - \\
15 & 1,770 & - \\
16 & 1,593 & - \\
17 & 1,943 & - \\
18 & 1,940 & - \\
19 & 1,937 & - \\
20 & 1,757 & - \\
\hline Average & 1,774 & - \\
\hline & & - \\
\hline
\end{tabular}

outside of the range of error; therefore, $65 \%$ of the pulses are accepted as the reproducibility sensing percent, with a continuous average service of $9.3 \mathrm{hr}$ for each layer, equivalent to 20 pulses. In the same way as in the previous test, five layers were evaluated for pulses of $0.4 \mathrm{~mL}$. The same methodology 


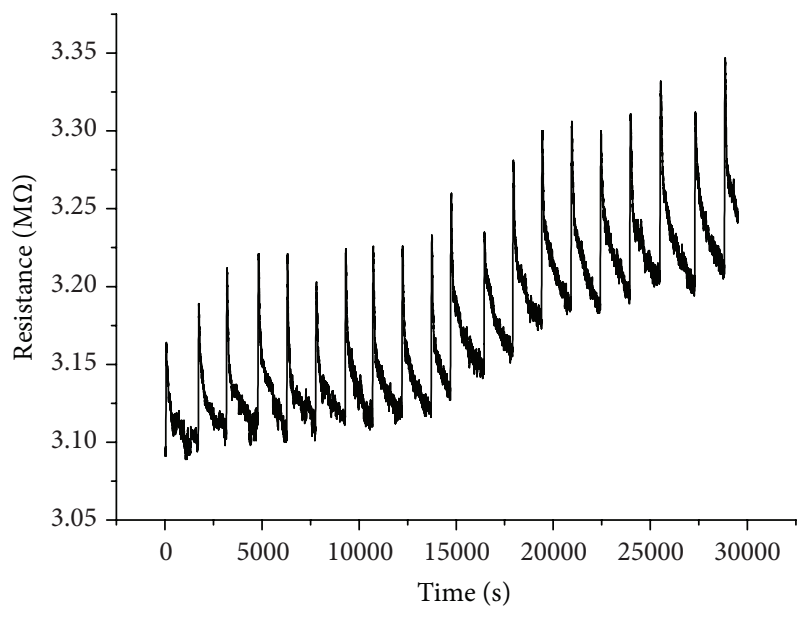

(a)

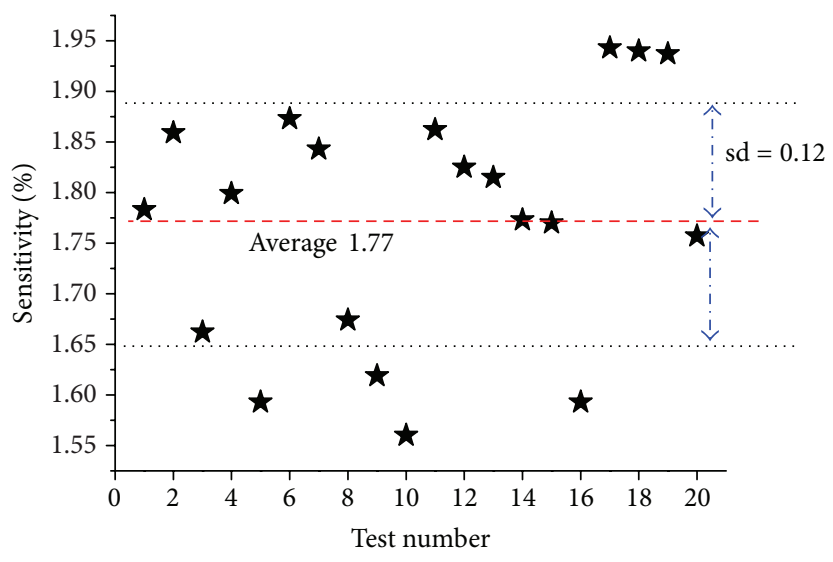

(b)

FIGURE 4: For the MST-3a sample: (a) MST experiment to $0.1 \mathrm{~mL}$ THF and (b) reproducibility to the MST experiment at $0.1 \mathrm{~mL}$ THF.

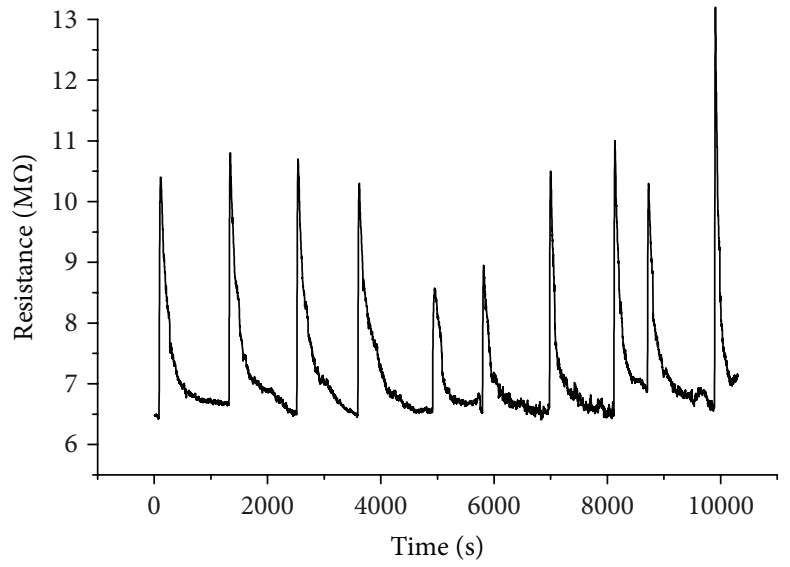

(a)

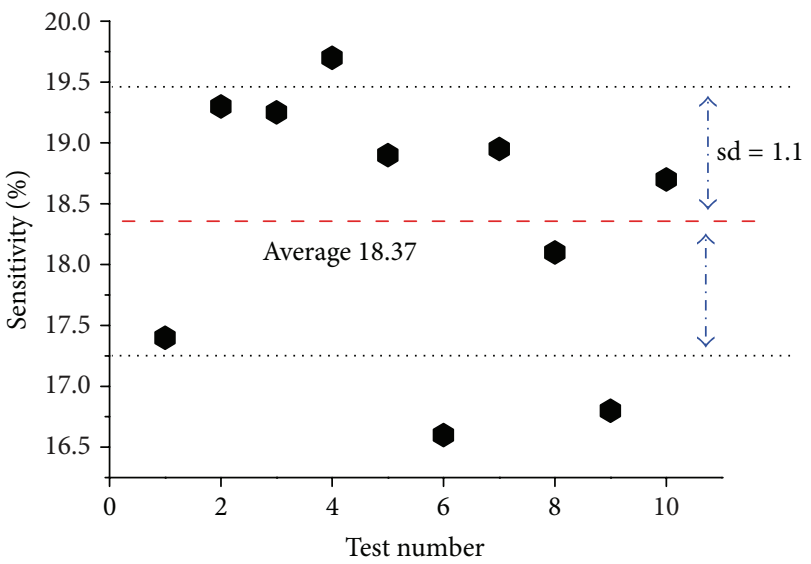

(b)

FIGURE 5: For the MST-3c sample: (a) MST experiment to $0.4 \mathrm{~mL}$ THF and (b) reproducibility to the MST experiment at $0.4 \mathrm{~mL}$ of THF for the same sample.

was used to evaluate five layers with pulses of $0.4 \mathrm{~mL}$. The original resistance of the layers is shown in Table 1.

A multiple sensing test using $0.4 \mathrm{~mL}$ THF is shown in Figure 5(a). It is noted that the sensitivity is higher for pulses of $0.4 \mathrm{~mL}$ than for $0.1 \mathrm{~mL}$; however, at high volumes the deterioration of the sensor layer is faster. This is detected by the lower number of pulses of $0.4 \mathrm{~mL}$ THF in which the layer senses before it is damaged. The average sensitivity of the five evaluated layers is shown in Table 3. The number of performed tests was, on average, 10 pulses with an error of $\pm 5.08 \%$ in comparison with the average value $(18.37 \%)$. The results are shown in Figure 5(b), where the average sensitivity is the dotted line; the solid lines represent the range of acceptable error for reproducibility. Thirty percent of the injected pulses are outside of this range, and therefore $70 \%$ of the pulses are reproducible with $3.5 \mathrm{hr}$ of continuous sensing. While with $0.1 \mathrm{~mL}$ it is possible to detect 20 successive pulses, with $0.4 \mathrm{~mL}$, the error is $\pm 5 \%$. This deviation can be due to a change in the accommodation of the conductive networks produced by the carbon black particles in the polymer matrix. The carbon black particles undergo a modification of their initial or previous pulse. It can be seen that the response and desorption times depend on the THF concentration. For quantities lower than $0.5 \mathrm{~mL}$, the response times tend to be greater than 2-10 s. The sensitivity percent is greater for higher THF quantities, on the order of $180 \%$, and the desorption times tend to be greater than $5 \mathrm{~min}$. Low THF concentrations tend to be retained with higher intensity, and this is evidenced by long desorption times.

It can be seen that the response and desorption times depend on the THF concentration. For concentrations lower than $0.5 \mathrm{~mL}$, the response times tend to be greater than 2$10 \mathrm{~s}$ for amounts above $0.5 \mathrm{~mL}$ THF. The sensitivity percent is greater than the unit for lower THF quantities, but for higher concentrations than $0.4 \mathrm{~mL}$ the sensitivity percent is in 
the order of $180 \%$, and the desorption time similarly tends to be greater than $5 \mathrm{~min}$. Small THF concentrations tend to be retained with higher intensity, which is evidenced by the long desorption times.

Some authors, such as Kaur et al. [25], note that a short response time in a chemiresistor is $45 \mathrm{~s}$; Chen et al. [26] noted that a sensor of WPU/3.5 wt.\% CB exposed to $10 \mathrm{ppt}$ (parts per trillion) of acetone exhibits response times from 150 to $400 \mathrm{~s}$, and a short desorption time for the same sensor ranges from 50 to $100 \mathrm{~s}$. Ding et al. [27] reported a desorption time (less than or equal to $7 \mathrm{~s}$ ) in a gas sensor based on nanofibers manufactured via electrospinning. There is not a precise time designed to define a short or long response. However, one might conclude that the same compound exhibits a range in the parameters depending on the type of sensor and on the specific application.

\section{Conclusions}

Conductive layers of modified cellulose and 10 wt.\% CB composites were prepared by spinning. Their ability to detect THF vapors was evaluated by determining parameters: sensitivity percent, response and desorption times, reproducibility, and durability in two types of experiments, PST and MST. The sensitivity percent from PST experiments allowed evaluation of the potential to effectively sense THF in the range from 0.1 to $1.0 \mathrm{~mL}$. Sensing effectiveness increased as the amount of THF increased, reaching a maximum of $180 \%$ at $1.0 \mathrm{~mL}$ THF. The response times for the same experiment were in the range of 2-24s while desorption times decreased from 12 to $2.3 \mathrm{~min}$. MST experiments were undertaken to determine reproducibility and durability at constant THF volumes, 0.1 and $0.4 \mathrm{~mL}$. For both volumes, the reproducibility was around $65 \%$, and the durability decreased at a half from 20 to 10 pulses when the amount of solvent increases from 0.1 to $0.4 \mathrm{~mL}$. Those results indicate that ACAB with $10 \mathrm{wt} . \% \mathrm{CB}$ composites effectively detects THF.

\section{Conflict of Interests}

The authors of the paper do not have a direct financial relation or conflict of interests with the commercial identities mentioned in this paper. The commercial trademarks, SigmaAldrich and Chemical and Electron Microscopy Sciences mentioned in this paper, are only for guaranteeing the reproducibility of the experiments, not leading to a conflict of interests for any of the authors.

\section{Acknowledgment}

The authors gratefully acknowledge finantial support by PROMEP-SEP for "Red de Compuestos Poliméricos, Propiedades y Aplicaciones."

\section{References}

[1] M. Castro, B. Kumar, J. F. Feller, Z. Haddi, A. Amari, and B. Bouchikhi, "Novel e-nose for the discrimination of volatile organic biomarkers with an array of carbon nanotubes (CNT) conductive polymer nanocomposites (CPC) sensors," Sensors and Actuators B, vol. 159, no. 1, pp. 213-219, 2011.

[2] M. S. Freund and N. S. Lewis, "A chemically diverse conducting polymer-based 'electronic nose', Proceedings of the National Academy of Sciences of the United States of America, vol. 92, pp. 2652-2656, 1995.

[3] B. J. Doleman and N. S. Lewis, "Comparison of odor detection thresholds and odor discriminabilities of a conducting polymer composite electronic nose versus mammalian olfaction," Sensors and Actuators B, vol. 72, no. 1, pp. 41-50, 2001.

[4] A. V. Shevade, M. A. Ryan, M. L. Homer, A. M. Manfreda, H. Zhou, and K. Manatt, "Molecular modeling of polymer composite-analyte interactions in electronic nose sensors," Sensors and Actuators B, vol. 93, no. 1-3, pp. 84-91, 2003.

[5] A. V. Shevade, M. L. Homer, C. J. Taylor et al., "Correlating polymer-carbon composite sensor response with molecular descriptors," Journal of the Electrochemical Society, vol. 153, no. 11, Article ID 026611JES, pp. H209-H216, 2006.

[6] M. A. Ryan, H. Zhou, M. G. Buehler et al., "Monitoring space shuttle air quality using the jet propulsion laboratory electronic nose," IEEE Sensors Journal, vol. 4, no. 3, pp. 337-347, 2004.

[7] S. V. Patel, M. W. Jenkins, R. C. Hughes, W. G. Yelton, and A. J. Ricco, "Differentiation of chemical components in a binary solvent vapor mixture using carbon/polymer composite-based chemiresistors," Analytical Chemistry, vol. 72, no. 7, pp. 1532$1542,2000$.

[8] N. Tsubokawa, Y. Shirai, M. Okazaki, and K. Maruyama, "A novel gas sensor from crystalline polymer-grafted carbon black: responsibility of electric resistance of composite from crystalline polymer-grafted carbon black against solvent vapor," Polymer Bulletin, vol. 42, no. 4, pp. 425-431, 1999.

[9] E. J. Severin, B. J. Doleman, and N. S. Lewis, "An investigation of the concentration dependence and response to analyte mixtures of carbon black/insulating organic polymer composite vapor detectors," Analytical Chemistry, vol. 72, no. 4, pp. 658-668, 2000.

[10] J. R. Li, J. R. Xu, M. Q. Zhang, and M. Z. Rong, "Carbon black/polystyrene composites as candidates for gas sensing materials," Carbon, vol. 41, no. 12, pp. 2353-2360, 2003.

[11] M. C. Burl, B. C. Sisk, T. P. Vaid, and N. S. Lewis, "Classification performance of carbon black-polymer composite vapor detector arrays as a function of array size and detector composition," Sensors and Actuators B, vol. 87, no. 1, pp. 130-149, 2002.

[12] E. G. Berríos, T. Gao, D. Walker, B. S. Brunschwig, and N. S. Lewis, "Composites of carboxylate-capped $\mathrm{TiO}_{2}$ nanoparticles and carbon black as chemiresistive vapor sensors," Sensors and Actuators B, vol. 158, p. 17, 2011.

[13] M. Matsuguchi, K. Asahara, and T. Mizukami, "Highly sensitive toluene vapor sensors using carbon black/amino-functional copolymer composites," Journal of Applied Polymer Science, vol. 127, no. 4, pp. 2529-2535, 2013.

[14] E. S. Tillman and N. S. Lewis, "Mechanism of enhanced sensitivity of linear poly(ethylenimine)-carbon black composite detectors to carboxylic acid vapors," Sensors and Actuators B, vol. 96, no. 1-2, pp. 329-342, 2003.

[15] B. J. Doleman, R. D. Sanner, E. J. Severin, R. H. Grubbs, and N. S. Lewis, "Use of compatible polymer blends to fabricate arrays of carbon black-polymer composite vapor detectors," Analytical Chemistry, vol. 70, no. 13, pp. 2560-2564, 1998.

[16] B. C. Sisk and N. S. Lewis, "Vapor sensing using polymer/carbon black composites in the percolative conduction regime," Langmuir, vol. 22, no. 18, pp. 7928-7935, 2006. 
[17] G. Sakale, M. Knite, V. Teteris, V. Tupureina, S. Stepina, and E. Liepa, "The investigation of sensing mechanism of ethanol vapour in polymer-nanostructured carbon composite," Central European Journal of Physics, vol. 9, no. 2, pp. 307-312, 2011.

[18] M. C. Lonergan, E. J. Severin, B. J. Doleman, S. A. Beaber, R. H. Grubbs, and N. S. Lewis, "Array-based vapor sensing using chemically sensitive, carbon black-Polymer resistors," Chemistry of Materials, vol. 8, no. 9, pp. 2298-2312, 1996.

[19] L. Niu, Y. Luo, and Z. Li, "A highly selective chemical gas sensor based on functionalization of multi-walled carbon nanotubes with poly(ethylene glycol)," Sensors and Actuators B, vol. 126, no. 2, pp. 361-367, 2007.

[20] C. Wei, L. Dai, A. Roy, and T. B. Tolle, "Multifunctional chemical vapor sensors of aligned carbon nanotube and polymer composites," Journal of the American Chemical Society, vol. 128, no. 5, pp. 1412-1413, 2006.

[21] S. H. Lopez and E. V. Santiago, "Acrylated-epoxidized soybean oil-based polymers and their use in the generation of electrically conductive polymer composites," in Soybean-Bio-Active Compounds, H. A. El-Shemy, Ed.

[22] R. San Juan-Farfán, S. Hernández-López, G. Martínez-Barrera, M. A. Camacho-López, and E. Vigueras-Santiago, "Electrical characterization of polystyrene-carbon black composites," Physica Status Solidi, vol. 2, no. 10, pp. 3762-3765, 2005.

[23] S. H. López, E. V. Santiago, M. M. Rojas, and D. R. Contreras, "Changes in the electrical resistivity of thin-films for polymer composites induced by heating-cooling cycles," Journal of Materials Science and Engineering B, vol. 2, no. 12, pp. 601-6010, 2012.

[24] M. Kaur, D. K. Aswal, and J. V. Yakhmi, "Chemiresistor gas sensors: materials, mechanisms and fabrication," in Science and Technology of Chemiresistor Gas Sensors, chapter 2, pp. 33-93, 2007.

[25] M. Kaur, D. K. Aswal, and J. V. Yakhmi, "Chemiresistor gas sensors: materials, mechanisms and fabrication," in Science and Technology of Chemiresistor Gas Sensors, pp. 33-93, 2007.

[26] S. G. Chen, J. W. Hu, M. Q. Zhang, M. Z. Rong, and Q. Zheng, "Improvement of gas sensing performance of carbon black/ waterborne polyurethane composites: effect of crosslinking treatment," Sensors and Actuators B, vol. 113, no. 1, pp. 361-369, 2006.

[27] B. Ding, M. Wang, J. Yu, and G. Sun, "Gas sensors based on electrospun nanofibers," Sensors, vol. 9, no. 3, pp. 1609-1624, 2009. 

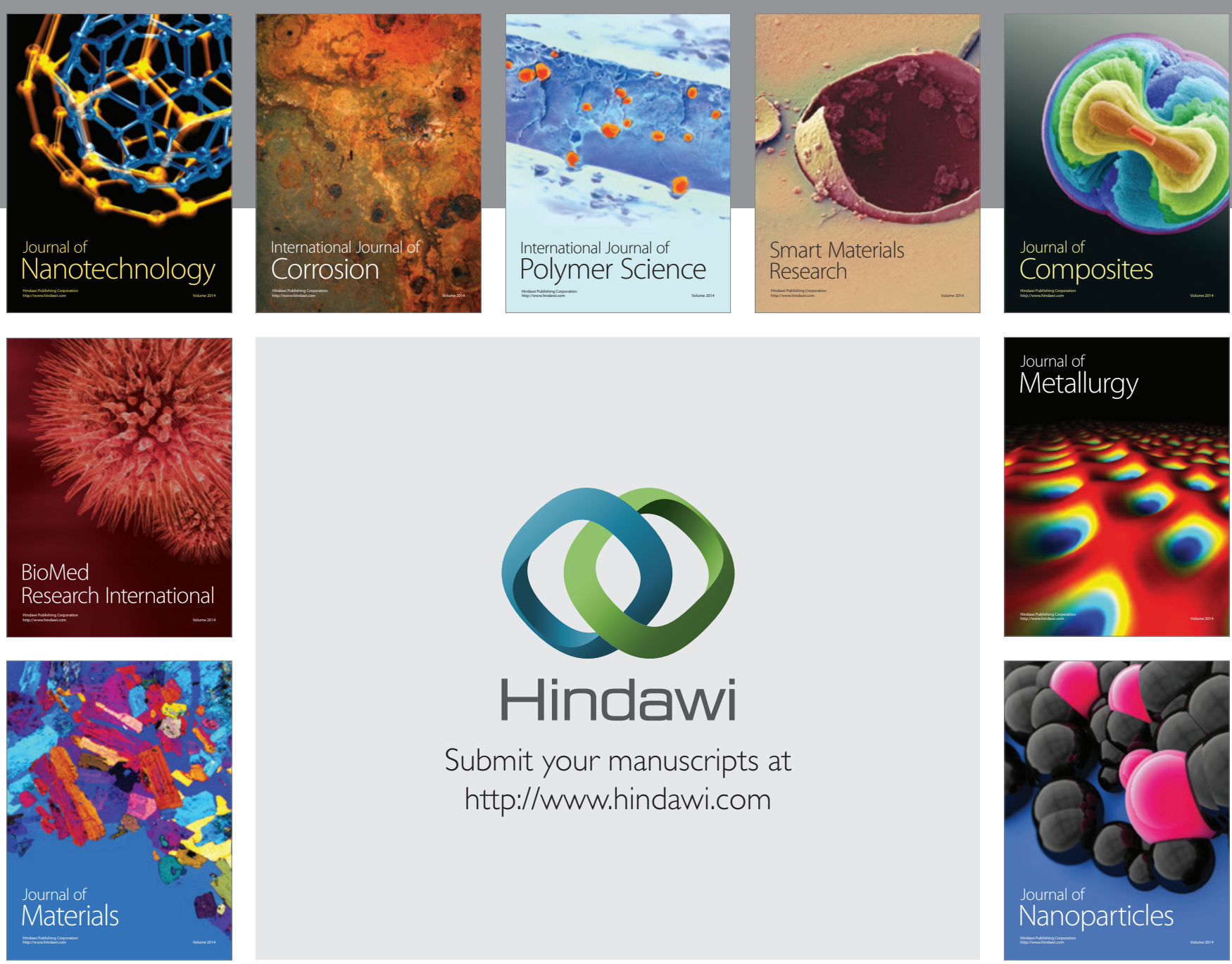

Submit your manuscripts at http://www.hindawi.com
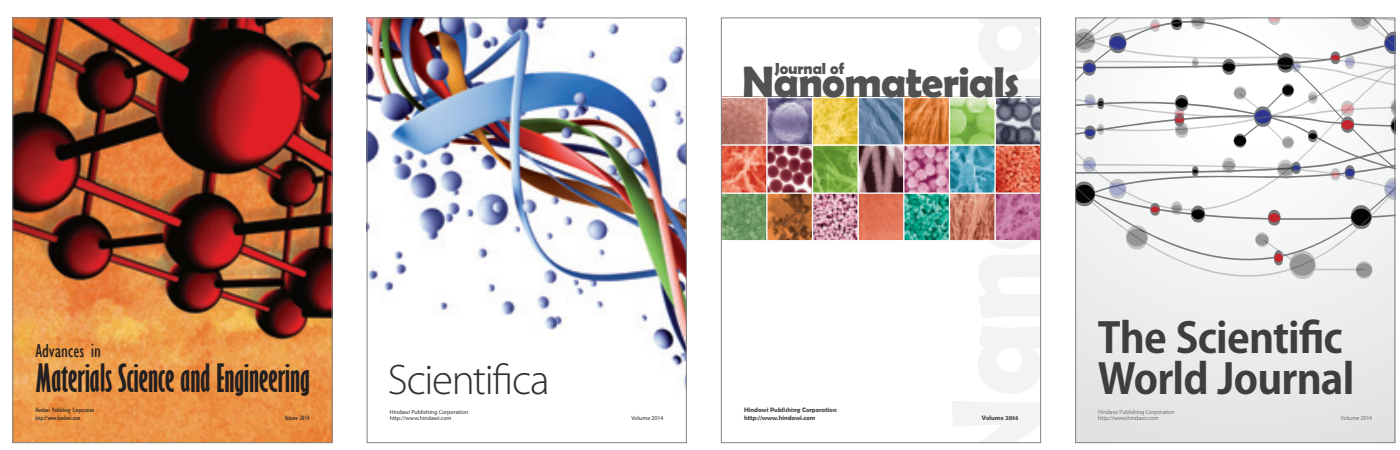

\section{The Scientific World Journal}
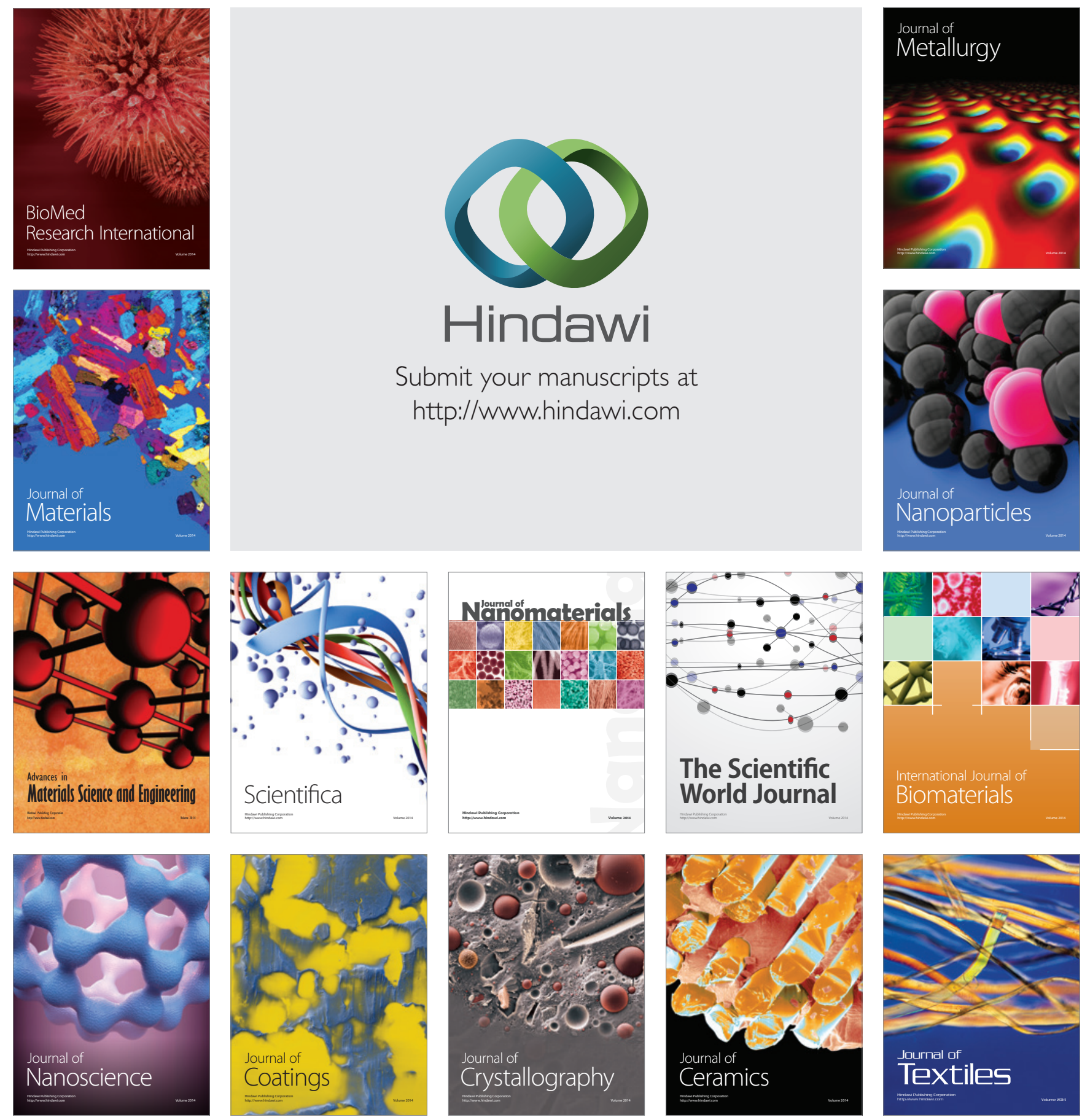